University of Massachusetts Amherst

ScholarWorks@UMass Amherst

1993

\title{
Determination of Inorganic Arsenic and Its Organic Metabolites in Urine by Flow Injection Hydride Generation Atomic Absorption Spectrometry
}

Julian Tyson

University of Massachusetts Amherst

C P. Hanna

University of Massachusetts Amherst

S McIntosh

Follow this and additional works at: https://scholarworks.umass.edu/chem_faculty_pubs

Part of the Chemistry Commons

\section{Recommended Citation}

Tyson, Julian; Hanna, C P.; and McIntosh, S, "Determination of Inorganic Arsenic and Its Organic Metabolites in Urine by Flow Injection Hydride Generation Atomic Absorption Spectrometry" (1993). Clinical Chemistry. 1307.

Retrieved from https://scholarworks.umass.edu/chem_faculty_pubs/1307 


\section{Determination of Inorganic Arsenic and Its Organic Metabolites in Urine by Flow-Injection Hydride Generation Atomic Absorption Spectrometry Christopher P. Hanna, ${ }^{1}$ Julian F. Tyson, ${ }^{1,2}$ and Susan McIntosh ${ }^{3}$}

A method has been developed for the determination of inorganic arsenic [As(III) and As(M)] and its organic metabolites (monomethylarsenic and dimethylarsenic) in urine by flow-injection hydride generation atomic absorption spectrometry. The nontoxic seafood-derived arsenobetaine and arsenocholine species were first separated by a solid-phase extraction procedure. The remaining sample was digested with a mixture of nitric and sulfuric acids and potassium dichromate, followed by attack with hydrogen peroxide. The resulting As( $(V)$ was reduced to As(III) with potassium iodide in hydrochloric acid before injection into the flow-injection manifold. The percentage analytical recoveries (mean $\pm 95 \%$ confidence interval) of various arsenic species added to a urine specimen at 250 $\mu \mathrm{g} / \mathrm{L}$ were $108 \pm 2,112 \pm 11,104 \pm 7$, and $95 \pm 5$ for As(III), As(V), monomethylarsenic, and dimethylarsenic, respectively. For the determination of arsenic in Standard Reference Material 2670 (toxic metals in human urine), results agreed with the certified value $(480 \pm 100 \mu \mathrm{g} / \mathrm{L})$. Analyses of samples for the Centre de Toxicologie du Quebec, containing seafood-derived species, demonstrated the viability of the separation procedure. Detection limits were between 0.1 and $0.2 \mu \mathrm{g} / \mathrm{L}$ in the solution injected into the manifold, and precision at $10 \mu \mathrm{g} / \mathrm{L}$ was between $2 \%$ and $3 \%$ (CV). These preliminary results show that the method might be applicable to determinations of arsenic in a range of clinical urine specimens.

Indexing Terms: mono- and dimethylarsenic - toxicology

When a person suffers from an arsenic overdose, be it from acute or chronic exposure, the arsenic concentrations in the body are often monitored by the determination of total arsenic in the individual's urine. Flow-injection hydride generation atomic abeorption opectrometry (FI-HGAAS) is an attractive analysis proceture for this determination, because of its relative simplicity and high sensitivity. ${ }^{4}$ This method also has the salient benefits of excellent sample throughput, reduced sample size, decreased possibility of sample contamination, and enhanced tolerance for interfering elements in comparison with conventional batch procechure. These aspects of FI-HGAAS have been recently reviewed (1).

\footnotetext{
${ }^{1}$ Chemistry Department, University of Maseachusetts at Amherst, Amherst, MA 01003.

${ }_{2}$ Author for correspondence.

3 Inorganic Analyaia Division, The Perkin-Elmer Corp., 50 Danbury Rd., Wilton, CT 06897.

4 Nonstandard abbreviations: FI-HGAAS, flow-injection hydride generation atomic abeorption spectrometry; MMA, monomethylareenic, DMA, dimethylareenic; SRM, Standard Reference Material; NIST, National Institute of Standards and Technology.

Received December 18, 1992; accepted February 17, 1993.
}

However, the direct determination of total arsenic in urine by FI-HGAAS can lead to erroneous results. The source of this error is the transformation of arsenic that takes place in the body. For example, inorganic areenic ingested (through inhalation, food, or drink) as $\mathrm{AB}_{\theta}(\mathrm{V})$ is reduced to $\mathrm{As}_{\text {(III). The }} \mathrm{As}_{\mathrm{B}}$ (III) is then oubjected to a stepwise methylation process-first to monomethylarsenic (MMA), and then to dimethylarsenic (DMA). If the arsenic is ingested in the lese-toxic MMA or DMA forms, or in the nontoxic seafood-derived forms of arso nobetaine $\left[\left(\mathrm{CH}_{3}\right)_{9} \mathrm{As}^{+} \mathrm{CH}_{2} \mathrm{CO}_{2}\right.$-] and arsenocholine $\left[\left(\mathrm{CH}_{3}\right)_{9} \mathrm{As}^{+} \mathrm{CH}_{2} \mathrm{CH}_{2} \mathrm{OH}\right.$, no process of methylation or demethylation appears to occur, and these forms are excreted unchanged (2). Because these arsenic species can be present in unknown proportions in each urine sample $(3,4)$, and because the arsenic sensitivity obtained can vary from species to species in HGAAS (5), a sample pretreatment procedure is necessary to convert the various forms of arsenic to one species.

Several approaches have been taken to convert organoarsenic species to the inorganic state, most of which involve some sort of acid digestion. Investigators have used penchloric acid digestions with various degrees of success $(6,7)$. The highly oxidative characteristic of perchloric acid is well understood, but it also is known to be very dangerous, requires specialized ventilation facilities, and has been implicated in incomplete arsenic recuveries $(7,8)$. To avoid the difficulties aseociated with penchloric acid, investigators have also used nitric acid/ sulfuric acid digestions, both without catalysts (5) and with $\mathrm{V}_{2} \mathrm{O}_{5}(5,9)$ or $\mathrm{K}_{2} \mathrm{Cr}_{2} \mathrm{O}_{7}(5)$ catalysts. These proco dures also resulted in various degrees of success.

Investigators have attempted to automate the decomposition of organoarsenic species by using continuousflow and flow-injection methodology $(10,11)$. These automated methods have involved concentrated acids and strong oxidizing agents in continuous-flow assays (10), or ultraviolet radiation in highly basic persulfate in flow-injection techniques (11). Although these methods quantitatively decompose all of the organoarsenic species present in aqueous solutions, they do not appear to be applicable to organoarsenic species in highly oxidizable matrices (11), e.g., urine.

Recently, investigators have shown the utility of using electrothermal atomization AAS with in situ oxidation of various toxic and nontoxic arsenic species for the direct determination of total arsenic in urine (12). These same investigators developed a rapid solidphase extraction procedure for removing the nontoxic sesfood-derived arsenic species (arsenobetaine and arse nocholine) before the direct determination of the total remaining (i.e., toxic) arsenic portion (13). This novel 
analysis approach avoids costly chromatographic procedures for the removal of the nontoxic arsenic species before the determination, but still requires the use of very expensive instrumentation. Furthermore, costs continue to be incurred through the instrument's maintenance and operation (e.g., graphite atomizers and palladium matrix modifiers).

Here we compare various nonperchloric acid digestion procedures for determining total arsenic in urine by FI-HGAAS. Rewveries from each procedure for inorganic and organoarsenic species are presented. The optimized digestion procedure was applied to Standand Reference Material (SRM) 2670 [Toxic Metals in Urine; from National Institute of Standands and Technology (NIST), Gaithersburg, MD], which is certified for total arsenic. The digestion procedure was also used with a certified urine sample (Le Centre de Toxicologie du Quebec, Quebec, Canada) in which the arsenic present is that resulting from the ingestion of a seafood diet, i.e., a source of nontoxic arsenobetaine and arsenocholine. This urine sample was digested and analyzed with and without the use of a rapid solid-phase extraction proce dure designed to remove the nontaxic, seafood-derived arsenic species from the urine matrix. The volatile hydride was generated by FI-HGAAS, utilizing both an off-line and on-line prereduction of $\mathrm{As}(\mathrm{V})$ to $\mathrm{As}$ (III). Each prereduction procedure results in a detection limit of $<10 \mu \& / \mathrm{L}$ total arsenic in urine, with quantitative recoveries being obtained for total arsenic in SRM 2670 and for quantities of $A_{s}(V)$ and DMA added to the "seafood arsenic" urine sample. The procedure does not require costly instrumentation, and all of the chemicals used are commonly found in any laboratory.

\section{Meterials and Methods \\ Apparatus}

A Perkin-Elmer (Norwalk, CT) 3100 atomic absorption spectrometer equipped with a Perkin-Elmer arsenic hollow cathode lamp operated at $18 \mathrm{~mA}$ was used for all determinations. The opectral bandpass was $0.7 \mathrm{~nm}$ at the 193.7-nm arsenic opectral line. A FIAS 200 flowinjection atomic spectrometry system was used to generate the hydride signal and was controlled by a Digital Equipment Corp. (Marlboro, MA) DECstation 316 sx. To avoid water passing into the quartz atomization cell from the manifold, we included a syringe filter $(2.0-\mathrm{cm}$ diameter, 0.5- $\mu \mathrm{m}$ pore size, polytetrafluoroethylene; Millipore, Bedford, MA) in the vapor transfer line. A CFM (Matthews, NC) Model MDS-81 microwave oven was used.

\section{Reagents}

Distilled, deionized water was produced by an E-Pure water purification system (Barnstead, Dubuque, IA). Concentrated reagent ACS-grade sulfuric acid (680 g/kg), nitric acid (700 g/kg), hydrochloric acid (380 g/kg) and "Optima"-grade hydrochloric acid (380 g/kg) were used as obtained from Fisher Scientific (Pittsburgh, PA), and diluted with distilled, deionized water as necessary. Sodium borohydride reagent solution was prepared by dissolving $4 \mathrm{~g}$ of sodium borohydride powder (Fisher Scientific) in $1 \mathrm{~L}$ of $0.5 \mathrm{~g} / \mathrm{L}$ sodium hydroxide solution. This was suction-filtered through no. 42 Whatman (Clifton, NJ) filter disks, and was prepared fresh daily. Hydrochloric acid carrier solution was prepared by diluting $100 \mathrm{~mL}$ of concentrated reagent ACS-grade hydrochloric acid to $1 \mathrm{~L}$ with distilled, deionized water and mixing thoroughly.

Standand solutions of $\mathrm{As}(\mathrm{V})$ were prepared by appropriately diluting a $1000 \mathrm{mg} / \mathrm{L}$ stock solution of $\mathrm{As}(\mathrm{V})$, and including the $100 \mathrm{~mL} / \mathrm{L}$ hydrochloric acid as a standard solution preservative. Standand solutions of $\mathrm{As}$ (III) were prepared by appropriately diluting a 1000 $\mathrm{mg} / \mathrm{L}$ stock solution of $\mathrm{As}(\mathrm{V})$ and prereducing the final standard to $\mathrm{As}$ (III) with $10 \mathrm{~mL}$ of $100 \mathrm{~g} / \mathrm{L}$ potassium iodide/100 $\mathrm{g} / \mathrm{L}$ ascorbic acid (both original solid forms from Fisher Scientific) and $10 \mathrm{~mL}$ of concentrated reagent ACS-grade hydrochloric acid for $15 \mathrm{~min}$ before final dilution with distilled, deionized water. Standand solutions of arsenic as MMA were prepared by dissolving $166.6 \mathrm{mg}$ of methylarsine dibromide $\left(\mathrm{CH}_{9} \mathrm{AsBr}_{2}\right.$, 100\%; Alfa, Ward Hill, MA) in $50 \mathrm{~mL}$ of distilled, deionized water. This resulted in $1000 \mathrm{mg} / \mathrm{L}$ arsenic as MMA, and was then diluted appropriately with distilled, deionized water. Standand solutions of arsenic as DMA were prepared by dissolving $285.6 \mathrm{mg}$ of cacodylic acid, sodium salt trihydrate $\left[\left(\mathrm{CH}_{3}\right)_{2} \mathrm{As}_{3}(\mathrm{O}) \mathrm{ONa} \cdot 3 \mathrm{H}_{2} \mathrm{O}\right.$, >99\%; Fluka, Ronkonkoma, NY] in $100 \mathrm{~mL}$ of distilled, deionized water. This resulted in $1000 \mathrm{mg} / \mathrm{L}$ arsenic as DMA, and was then diluted appropriately with distilled, deionized water.

Urine samples for arsenic species recoveries were prepared by adding known masses of arsenic as inorganic or organic species to known volumes of urine before digestion. All urine samples were either purchased or collected in accordance with the ethical standands prescribed by the University of Massachusetts, Amherst. If the samples were not to be digested and were to be analyzed directly, the procedure was as follows: (a) for off-line prereduction of the urine sample before direct analysis, $1 \mathrm{~mL}$ of arsenic-supplemented urine was prereduced as described above for the $\mathbf{A s}$ (III) standard solution, diluted to $100 \mathrm{~mL}$, and analyzed; or (b) for on-line prereduction of the urine sample before direct analysis, $2 \mathrm{~mL}$ of supplemented urine was diluted with distilled, deionized water to $100 \mathrm{~mL}$ and analyzed with the on-line prereduction manifold described below. NIST-certified SRM urine samples (Toxic Metals in Urine) were prepared by dissolving the freeze-dried preparation with $20.0 \mathrm{~mL}$ of distilled, deionized water and taking a given volume for digestion. The removal of arsenobetaine and arsenocholine from Le Centre de Toxicologie du Quebec-certified urine samples containing high amounts of these seafood-derived arsenic species was achieved through a procedure described by Nixon and Moyer (13). In brief, 1-mL Bond-Elut SCX cartridges (Varian, Harbor City, CA) were washed twice with $1 \mathrm{~mL}$ of $10 \mathrm{~mL} / \mathrm{L}$ nitric acid in $100 \mathrm{~mL} / \mathrm{L}$ ethanol. Two 1-mL aliquots of unsupplemented, $\mathrm{As}(\mathrm{V})$ - and DMA-supplemented "seafood arsenic" urine samples 
( $\mathrm{pH}<2$ ) were each passed through a column and the eluates were collected in 125-mL Erlenmeyer flasks. Six 1-mL washings of the columns were made with the ethanolic nitric acid solvent and the eluates were collected together with the original urine volumes. These 8-mL total volumes were then digested with the optimized digestion procedure (see below).

\section{Optimization}

The flow-injection manifold used for hydride generation from As(III) has been described and optimized previously (7); thus, we made no attempts at further optimization. This FI-HGAAS manifold used with offline prereduction of $\mathrm{As}(\mathrm{V})$ to $\mathrm{As}(\mathrm{III})$ is shown in Figure 1. The continuous-flow manifold used for on-line prereduction of $\mathrm{As}(\mathrm{V})$ to $\mathrm{As}$ (III) before FI-HGAAS has also been described and optimized previously (14), and no further optimization attempts were made. The FIHGAAS manifold used with continuous-flow on-line prereduction of $\mathrm{As}(\mathrm{V})$ to $\mathrm{As}(\mathrm{III})$ is shown in Figure 2.

The following digestion procedures were compared for their effectiveness in determining arsenic species added to urine. All digestion procedures, except that in the microwave oven, were performed under a hood.

$\mathrm{KMnO}_{4} / \mathrm{H}_{2} \mathrm{SO}_{4}$ (15). To $5 \mathrm{~mL}$ of urine containing 1000 $\mu \mathrm{g} / \mathrm{L} \mathrm{As}$ as added $\mathrm{As}(\mathrm{III}), \mathrm{As}(\mathrm{V})$, and DMA, we added $0.75 \mathrm{~g}$ of solid potassium permanganate and mixed this in a 100-mL beaker. We then added slowly, in 0.5-1-mL aliquots, $5 \mathrm{~mL}$ of concentrated sulfuric acid, allowing the rather vigorous reaction to subside before adding the next aliquot. The final digest was clarified by adding 1-1.5 mL of $250 \mathrm{~mol} / \mathrm{L}$ hydroxylamine hydrochloride. The digest was prereduced off-line as described above, diluted to $1 \mathrm{~L}$, and analyzed.

$\mathrm{H}_{2} \mathrm{O}_{2} / \mathrm{H}_{2} \mathrm{SO}_{4}$ (16). To $1 \mathrm{~mL}$ of urine containing 500 $\mu \mathrm{g} / \mathrm{L} \mathrm{As}$ as added $\mathrm{As}(\mathrm{V})$ and DMA, we added $5 \mathrm{~mL}$ of 300 $\mathrm{mL} / \mathrm{L}$ hydrogen peroxide and $5 \mathrm{~mL}$ of concentrated sulfuric acid and mixed these in an uncovered 125-mL Erlenmeyer flask. This was heated to $\sim 120^{\circ} \mathrm{C}$ on a hotplate, driving off water, oxygen, carbon dioxide, and other gaseous products. Once the boiling ceased, the

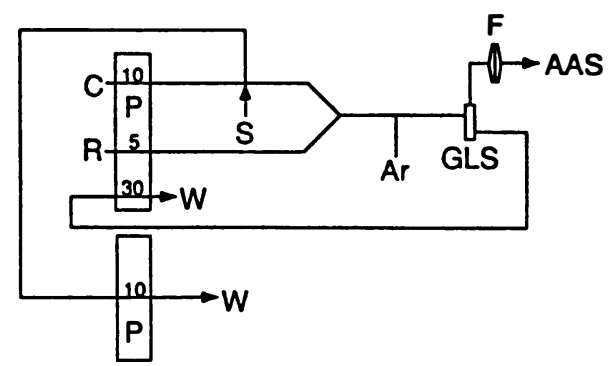

Fig. 1. Flow-injection manifold diagram for hydride generation, with off-line prereduction of As(N) to As(III)

$C, 100 \mathrm{~mL} L$ mydrochloric acid carrler stream; $A, 4 \mathrm{~g} L$ sodium borotiyditde in $0.5 \mathrm{~g} / \mathrm{L}$ reductant stream; $S, 500-\mu \mathrm{L}$ semple loop; $A r, 30 \mathrm{~mL} / \mathrm{min}$ argon purging stream; GLS, gas-liquid seperator supplied in the Perkin-Elmer FLS 200

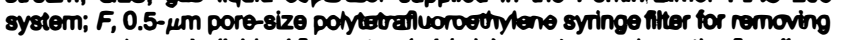
any water drope. Individual now rates $(\mathrm{mL} / \mathrm{min})$ are shown abovethe flow lines passing through each pump. $\boldsymbol{P}$. The distance between the carrier/reductant confluence point and argon addition is $10 \mathrm{~cm}$; from argon sodition to the gas-fiquid seperator is $30 \mathrm{~cm}$. W, waste

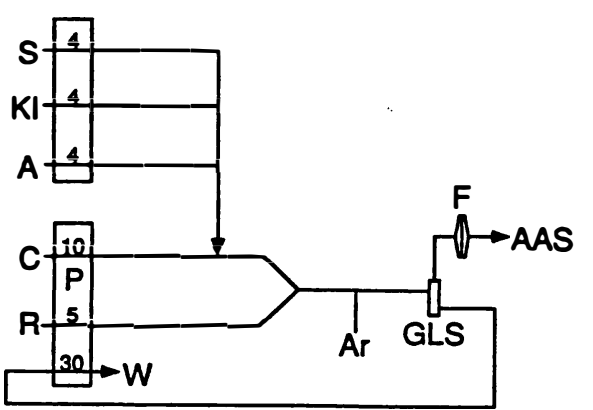

Fig. 2. Flow-injection manifold diagram for hydride generation, with continuous-flow on-line prereduction of As(M) to As(III)

All symbols as for Fig. 1, plus: $K, 300 \mathrm{~g} / \mathrm{L}$ potassium iodide in $50 \mathrm{~g} / \mathrm{L}$ escortic acid; and A, Optime-grade concentuated hydrochloric acid. The distence between the sample/W confluence point and acid addition is $60 \mathrm{~cm}$, and from acid addition to the sample loop is $60 \mathrm{~cm}$. Once the sample is merged and mixed in this continuous-llow manifold, the now is stopped for 30 \& before injection. This allows enough time for the As(M) in the semple stopped in the loop to reduce to $A_{B}$ (III)

digest was held at $120^{\circ} \mathrm{C}$ for $15 \mathrm{~min}$, then cooled, prereduced off-line as described above, diluted to 100 $\mathrm{mL}$, and analyzed.

$\mathrm{K}_{2} \mathrm{~S}_{2} \mathrm{O}_{8} / \mathrm{H}_{2} \mathrm{SO}_{4}$ (8). To $5 \mathrm{~mL}$ of urine containing 100 $\mu \mathrm{g} / \mathrm{L}$ As as added $\mathrm{As}(\mathrm{V})$ and DMA, we added $2.2 \mathrm{~g}$ of potassium persulfate and $5 \mathrm{~mL}$ of concentrated sulfuric acid and mixed these in an uncovered 125-mL Erlenmeyer flask. This was heated to $\sim 120^{\circ} \mathrm{C}$ on a hotplate, driving off water, oxygen, carbon dioxide, and other gaseous products. Once the boiling ceased, we added $1-\mathrm{mL}$ aliquots of $50 \mathrm{~mol} / \mathrm{L}$ potassium persulfate every 10 min for $30 \mathrm{~min}$ (total, four persulfate additions). The digest was then held at this temperature for $15 \mathrm{~min}$, cooled, preneduced off-line as described above, diluted to $100 \mathrm{~mL}$, and analyzed.

$H N O_{g} /$ microwave oven (17). We evaporated overnight at $60^{\circ} \mathrm{C} 10 \mathrm{~mL}$ of urine containing $100 \mu \mathrm{g} / \mathrm{L}$ As as added $\mathrm{As}(\mathrm{V})$ and DMA. This was reconstituted with $5 \mathrm{~mL}$ of concentrated nitric acid and was digested in the micro wave oven (in 100-mL CEM vessels) at $100 \%$ power for $2.5 \mathrm{~min}$ and $80 \%$ power for $3.5 \mathrm{~min}$ (eight vessels total). The digests were cooled, prereduced off-line as described above, diluted to $100 \mathrm{~mL}$, and analyzed.

$\mathrm{HNO}_{3} / \mathrm{H}_{2} \mathrm{SO}_{4} / \mathrm{H}_{2} \mathrm{O}_{2}(18,19)$. To $1 \mathrm{~mL}$ of urine containing $200 \mu \mathrm{g} / \mathrm{L}$ ss as added $\mathrm{As}(\mathrm{V})$ and DMA, we added $3 \mathrm{~mL}$ of concentrated nitric acid in an uncovered $125-\mathrm{mL}$ Erlenmeyer flask This was heated to $\sim 120^{\circ} \mathrm{C}$ on a hotplate until the volume was reduced to $\sim 1 \mathrm{~mL}$. The digeste were removed from the hotplate and $3 \mathrm{~mL}$ of concentrated sulfuric acid was added. The hotplate temperature was increased to $\sim 250{ }^{\circ} \mathrm{C}$ and the digests were reheated, driving off $\mathrm{SO}_{3}$ fumes, for $30 \mathrm{~min}$. The digests were removed from the hotplate and cooled for $1 \mathrm{~min}$, and $1 \mathrm{~mL}$ of $300 \mathrm{~mL} / \mathrm{L} \mathrm{H}_{2} \mathrm{O}_{2}$ was added. This was mixed and reheated until $\mathrm{SO}_{3}$ fumes resumed: The process of $\mathrm{H}_{2} \mathrm{O}_{2}$ addition/ $/ \mathrm{SO}_{3}$ fuming was performed four times. The final digests were cooled, prereduced off-line as described above, diluted to $100 \mathrm{~mL}$, and analyzed

$\mathrm{HNO}_{9} / \mathrm{H}_{2} \mathrm{SO}_{4} / \mathrm{V}_{2} \mathrm{O}_{6} / \mathrm{H}_{2} \mathrm{O}_{2}(5,9,18)$. To $2 \mathrm{~mL}$ of urine containing $250 \mu \& / \mathrm{L}$ As as added $\mathrm{As}(\mathrm{V})$ and DMA, we added $30 \mathrm{mg}$ of $\mathrm{V}_{2} \mathrm{O}_{5}$ solid and $5 \mathrm{~mL}$ of concentrated 
nitric acid in an uncovered 125-mL Erlenmeyer flask. This was heated to $\sim 120^{\circ} \mathrm{C}$ on a hotplate, reducing the volume to $\sim 1 \mathrm{~mL}$. The digests were removed from the hotplate and $5 \mathrm{~mL}$ of concentrated sulfuric acid was added. The hotplate temperature was increased to $\sim 250{ }^{\circ} \mathrm{C}$ and the digests were reheated, driving off $\mathrm{SO}_{3}$ fumes for $90 \mathrm{~min}$. The digesto were removed from the hotplate and cooled for $1 \mathrm{~min}$, and $1 \mathrm{~mL}$ of $300 \mathrm{~mL} / \mathrm{L}$ $\mathrm{H}_{2} \mathrm{O}_{2}$ was added. This was mixed and reheated until $\mathrm{SO}_{3}$ fumes resumed. The process of $\mathrm{H}_{2} \mathrm{O}_{2}$ addition/ $/ \mathrm{SO}_{3}$ fuming was repeated four times. The final digests were cooled, prereduced off-line as described above, diluted to $100 \mathrm{~mL}$, and analyzed.

$\mathrm{HNO}_{3} / \mathrm{H}_{2} \mathrm{SO}_{4} / \mathrm{K}_{2} \mathrm{Cr}_{2} \mathrm{O}_{7} / \mathrm{H}_{2} \mathrm{O}_{2}(5,18)$. The digestion procedure was identical to that for the method just described, except that $30 \mathrm{mg}$ of $\mathrm{K}_{2} \mathrm{Cr}_{2} \mathrm{O}_{7}$ was added instead of $30 \mathrm{mg}$ of $\mathrm{V}_{2} \mathrm{O}_{5}$.

\section{Determination of System Performance}

Aliquots of SRM 2670 were digested by the optimized procedure $\left(\mathrm{HNO}_{3} / \mathrm{H}_{2} \mathrm{SO}_{4} / \mathrm{K}_{2} \mathrm{Cr}_{2} \mathrm{O}_{7} / \mathrm{H}_{2} \mathrm{O}_{2}\right.$ ). The digests were prereduced off-line or on-line, and the results obtained were compared with the certified value. To determine the amount of bias encountered as a result of the presence of nontoxic, seafood-derived arsenic species in the urine, we digested and analyzed urine samples obtained from Le Centre de Toxicologie du Quebec using the optimized digestion procedure determined above. Once the amount of bias was determined, we supplemented the samples with inorganic $\mathrm{As}(\mathrm{V})$ and organic DMA and pretreated the samples with the rapid solidphase extraction procedure to remove the nontoxic arsenobetaine and arsenocholine species before digestion of the urine. These digests were prereduced off-line, and the results obtained were compared with the certified values and the known amount of arsenic added.

\section{Results and Discussion \\ Manifold Characteristics}

The off-line prereduction FI-HGAAS manifold (Figure 1) and the on-line preneduction FI-HGAAS manifold (Figure 2) were used to directly analyze undigested arsenic-supplemented urine samples, as well as supplemented urine samples that were digested before analysis. Calibration equations, precision data, and limits of detection for the two manifolds are shown in Table 1.

\section{Direct Determinations}

Preliminary investigations involved performing a direct determination of $\mathrm{As}$ in urine without a prior digestion protocol. The recoveries in Table 2 show that a digestion protocol is required to decompose the organoarsenic species for reliable determination of the total arsenic content. This is in disagreement with previously published reports, claiming full recoveries of organoarsenic species in direct analysis of urine by FIHGAAS without prior digestion (20). However, we obtained full recoveries for both inorganic arsenic species, using the direct analysis procedures described, with no formation of dense foam within the FI-HGAAS manifold. This shows that the on-line prereduction of $\mathrm{As}(\mathrm{V})$ to $\mathrm{As}$ (III) can proceed in matrices other than dilute acids (14), and that a direct determination of inorganic arsenic in urine by FI-HGAAS can be performed readily.

\section{Determinations after Sample Digestion}

Once we found that a digestion protocol would be necessary for the determination of total arsenic in urine, we examined a variety of protocols for their effect on recoveries of arsenic species. The digestions performed were originally designed for determining total arsenic in natural waters, wastewaters, or biological samples, or for determining other metals that are frequently assayed in urine.

The recoveries obtained for the various digestion procedures examined are shown in Table 2, with off-line prereduction of $\mathrm{As}(\mathrm{V})$ to $\mathrm{As}(\mathrm{III})$ before determination by FI-HGAAS. The initial observation made when one examines the recoveries for the first three (less aggressive) digestion procedures in Table 2 is that the inorganic arsenic species is less than fully or fully recovered, whereas the organic species (in these cases DMA) is not any more recovered than it was in the direct analysis procedure. Perhaps excess oxidizing agent present after the digestion is ended interferes by competing with the prereduction process, the hydride generation reduction process, or both. This could result in low recoveries for inorganic arsenic, whereas the organoarsenic species was not decomposed at all by the digestion procedure, so that recoveries were the same as without a digestion procedure.

In an attempt to fully decompose the organoarsenic

Table 1. Callbration Curves, Precision Data, and Umits of Detection for Both Fl-HGAAS Manlfolds

\begin{tabular}{|c|c|c|c|c|}
\hline & Bequanclon equetton & r & $\begin{array}{c}\text { Umit of detection, } \\
\text { As, } \text { rol }^{6}\end{array}$ & CV, \%० \\
\hline \multicolumn{5}{|c|}{ Off-line prereductions } \\
\hline Peak height & $H=\left(2.02 \times 10^{-2}\right) C+\left(1.26 \times 10^{-2}\right)$ & 1.000 & 0.07 & 3.5 \\
\hline Peak area & $A=(0.132) C+\left(4.80 \times 10^{-2}\right)$ & 0.999 & 0.36 & 2.3 \\
\hline \multicolumn{5}{|c|}{ On-line prereductions } \\
\hline Peak height & $H=\left(1.44 \times 10^{-2}\right) C+(0.054)$ & 0.996 & 0.17 & 2.3 \\
\hline Peak area & $A=\left(5.68 \times 10^{-2}\right) C+(0.181)$ & 0.993 & 0.69 & 0.5 \\
\hline
\end{tabular}


Table 2. Pencert Analytical Recoverles of Inorganic and Organic Areenic Specles Added to Urine as Determined by Peak-Holght Meesurements

\begin{tabular}{|c|c|c|c|c|}
\hline & \multicolumn{4}{|c|}{ Ansyed recovery, x" } \\
\hline & Ae(III) & Ans & mena & Din \\
\hline Direct analysts (off-line reduction) & $99 \pm 10(4)$ & $101 \pm 6(4)$ & NE $^{b}$ & $7 \pm 4(4)$ \\
\hline Direct analyols (on-line reduction) & $103 \pm 7(4)$ & $104 \pm 10(4)$ & NE & $15 \pm 5(4)$ \\
\hline $\mathrm{KMnO}_{4} \mathrm{H}_{2} \mathrm{SO}_{4}$ & $61 \pm 8(5)$ & $66 \pm 4(4)$ & NE & $4 \pm 11(4)$ \\
\hline $\mathrm{H}_{2} \mathrm{O}_{2} / \mathrm{H}_{2} \mathrm{SO}_{4}$ & NE & $83 \pm 7(4)$ & NE & $7 \pm 11(4)$ \\
\hline $\mathrm{K}_{2} \mathrm{~S}_{2} \mathrm{O}_{2} / \mathrm{H}_{2} \mathrm{SO}_{4}$ & NE & $99 \pm 5(4)$ & NE & $1 \pm 7(4)$ \\
\hline HNO / $\mu$-weve & NE & $2 \pm 2(3)$ & NE & $22 \pm 10(3)$ \\
\hline $\mathrm{HNO}_{3} / \mathrm{H}_{2} \mathrm{SO}_{4} / \mathrm{H}_{2} \mathrm{O}_{2}$ & NE & $102 \pm 6(4)$ & NE & $21 \pm 3(3)$ \\
\hline $\mathrm{HNO}_{3} / \mathrm{H}_{2} \mathrm{SO}_{4} \mathrm{~N}_{2} \mathrm{O}_{8} / \mathrm{H}_{2} \mathrm{O}_{2}$ & NE & $35 \pm 3(4)$ & NE & $20 \pm 10(4)$ \\
\hline $\mathrm{HNO}_{3} / \mathrm{H}_{2} \mathrm{SO}_{4} / \mathrm{K}_{2} \mathrm{Cr}_{2} \mathrm{O}_{7} / \mathrm{H}_{2} \mathrm{O}_{2}{ }^{\mathrm{C}}$ & $108 \pm 2(3)$ & $112 \pm 11(4)$ & $104 \pm 7(4)$ & $95 \pm 5(4)$ \\
\hline
\end{tabular}

opecies present in the urine sample, we examined more aggressive digestion protocols. The first of these was the application of microwave energy to a digesting acid (in this case, concentrated nitric acid) mixed with the urine sample in a closed vessel (17). It was very difficult to obtain meaningful recoveries (shown in Table 2) from this digestion, because of the $\mathrm{NO}_{x}$ fumes that were absorbed in the digested sample. These fumes can lead to erroneously high results for determinations by HGAAS (personal communication; E. Hasty, CEM Corp., Matthews, NC). The removal of these fumes from the digest requires open-vessel heating with concentrated sulfuric acid in the microwave oven, which is both potentially dangerous and labor intensive. We abandoned the use of the microwave oven in favor of simpler procedures.

It has been claimed (18) that the application of hydro gen peroxide with nitric and sulfuric acids will digest various difficult organic matrices, including paraffin oils and fats, as well as decompose several resistant organometallic compounds. Also, the use of hydrogen peraxide assists in ridding the sample of interfering $\mathrm{NO}_{x}$ fumes that may be present after digestion. We therefore applied a digestion protocol involving nitric acid, oulfuric acid, and hydrogen peroxide to the arsenic-supplemented urine samples, in an attempt to fully digest the matrix and then decompose the organoarsenic species present. Although recovery of the organoarsenic species DMA was incomplete, it was more than that of the less aggreasive digestion procedures (Table 2).

Because the As-C bond appeared to be starting to break, we decided that including oxidizing agents would expedite this process. $\mathrm{V}_{2} \mathrm{O}_{5}$ and $\mathrm{K}_{2} \mathrm{Cr}_{2} \mathrm{O}_{7}$ were applied because of their proven ability to assist in this decomposition process $(5,9,18)$. Also, the amount of time the oulfuric acid was allowed to give off $\mathrm{SO}_{3}$ fumes before the addition of $\mathrm{H}_{2} \mathrm{O}_{2}$ was increased from $30 \mathrm{~min}$ (without an oxidiring agent) to $90 \mathrm{~min}$, in an attempt to further enhance the degree of As-C bond breakage. As Table 2 shows, for digestion with the oxidizing agent $\mathrm{V}_{2} \mathrm{O}_{5}$ the recovery of DMA was similar to that without the $\mathrm{V}_{2} \mathrm{O}_{5}$, and some of the inorganic arsenic species were lost. This may be due to an excess of axidative power left in the catalyst once the digestion is completed. We saw no formation of a precipitate in the $\mathrm{V}_{2} \mathrm{O}_{5}$-assisted digestion at any point; moreover, the digest retained some of its original blue color, implying the presence of V(V). This latter may interfere with the prereduction process, the hydride generation reduction process, or both, by presenting the opportunity for a competing oxidation process to occur.

The use of $\mathrm{K}_{2} \mathrm{Cr}_{2} \mathrm{O}_{7}$ as oxidizing agent led to more success than $\mathrm{V}_{2} \mathrm{O}_{5}$ (Table 2). Both inorganic species [As(III) and $\mathrm{As}(\mathrm{V})$ ] and both organic species (MMA and DMA) were fully rewovered when added to urine. Possibly no oxidative power was left in the $\mathrm{K}_{2} \mathrm{Cr}_{2} \mathrm{O}_{7}$ oxidizing agent after the digeotion, as evidenced by the formation of a purple precipitate film at the bottom of the Erlenmeyer digesting flask This would imply the conversion of CrIVI) to Cr(III), thus obviating the oppurtunity for a competing oxidation process to occur in the prereduction step or the hydride generation process.

\section{System Performance Characteristics}

The $\mathrm{HNO}_{9} / \mathrm{H}_{2} \mathrm{SO}_{4} / \mathrm{K}_{2} \mathrm{Cr}_{2} \mathrm{O}_{7} / \mathrm{H}_{2} \mathrm{O}_{2}$ digertion procedure for total arsenic in urine by FI-HGAAS was validated by digesting 2.0-mL aliquots of SRM 2670 as described above. The resulting digests were either preneduced off-line as described previously, diluted to $100 \mathrm{~mL}$, and analyzed, or prereduced on-line after dilution to $100 \mathrm{~mL}$. Both prereduction procedures led to quantitative recoveries for total arsenic in SRM 2670: $540 \pm 19$ and $530 \pm$ $42 \mu g / L$, respectively (mean and 95\% confidence intervals, $n=3$ each), vs the NIST certified value of $480 \pm$ $100 \mu \mathrm{g} / \mathrm{L}$. To further evaluate oystem performance, we assessed the digestion and FI-HGAAS analysis of urine samples with high concentrations of nontoxic seafoodderived arsenic (Table 3). Because the extraction proce dure led to the detection of no arsenic in the resulting digest, we conclude that the extraction procedure is imperative if a potentially high bias resulting from the presence of nontoxic seafood-derived arsenic species is to be avoided. To determine the performance of the extraction procedure in the presence of toxic forms of arsenic, 
Table 3. Nontoxic Sectood-Dertved Areenic Species and Added Toxic Species Dotermined in Le Centre de Toxicologie du Qubboccartiled Urine Samples

\begin{tabular}{|c|c|c|}
\hline \multirow[b]{2}{*}{ samph } & \multicolumn{2}{|c|}{ As, mol (beck heloht)" } \\
\hline & Epectind & Found \\
\hline S9201 & 270 & $21 \pm 5$ \\
\hline 5205 & 195 & $19 \pm 7$ \\
\hline S9201 SPE & - & ND \\
\hline S9201 AsM \& SPE & 250 & $279 \pm 7$ \\
\hline S9201 DMA \& SPE & 250 & $234 \pm 8$ \\
\hline
\end{tabular}

we added $A s(V)$ and DMA, $250 \mu g / L$, to a urine sample that contained a high amount of seafood-derived arsenic. The recoveries obtained for these arsenic species pretreated with the extraction procedure are also shown in Table 3. As can be seen, the rapid solid-phase extraction procedure in conjunction with the simple $\mathrm{HNO}_{3} /$ $\mathrm{H}_{2} \mathrm{SO} / \mathrm{K}_{2} \mathrm{Cr}_{2} \mathrm{O}_{7} / \mathrm{H}_{2} \mathrm{O}_{2}$ digestion protocol leads to the quantitative determination of the toxic species of arsenic found in urine by FI-HGAAS, and the nontoxic seafood-derived arsenic species are removed from the measurement altogether.

Although the results obtained with the limited range of sample materials reported here show that accurate analyses have been performed, we recognize that we have not demonstrated the use of the method for a range of urine samples containing different amounts of possible matrix interferences (e.g., proteinuris, hemoglobinuris, salicylates, ascorbate, radiocontrast materials). However, these preliminary results are sufficiently encouraging to warrant further studies (day-to-day precision, run-to-run precision, analysis of urine samples from occupationally exposed workers) by a laboratory with appropriate access to these types of samples.

The Perkin-Elmer Corp. is gratefully acknowledged for financial ouppurt and proviaion of equipment for this research. We thank Tony Kruscheveks of the University of Massachusetto, Paul Ullucci of ESA Lahuratories, and David Niron of the Mayo Clinic for many very helpful discussions.

\section{Reforences}

1. Tyson JF. Flow injection atomic spectrometry. Sp=ntrochim Acta Rev 1991;14:169-233.

2. Braman RS. Environmental reaction and analysis methods. In:
Fowler R, ed. Biological and environmental effects of arsenic. Amstendam: Elsevier Science Publishers, 1983:141-54.

3. Ullucci PA. Arenic testing. "for a healthier environment." Bedford, MA: ESA Lab Note, 1992.

4. Baselt RC. Biological monitoring methods for industrial chemicals, 2nd ed. Littleton, MA. PSG Publishing, 1988:28-34.

5. Webb DR, Carter DE. An improved wet digestion procedure for the analyzis of total areenic in biological samples by direct hydride atomic abeorption epectrophotometry. J Anal Toxicol 1984;8:11823.

6. Cox DH. Arsine evolution-electrothermal atomic absorption method for the determination of nanogram levels of total arsenic in urine and water. J Anal Toxicol 1980;4:207-11.

7. Welz B, Schubert-Jacobs M. Evaluation of a flow injection system and optimization of parameters for hydride generation atomic abeorption spectrometry. At Spectroec 1991;12:91-104.

8. Shaikh AU, Tallman DE. Specieo-penific analysio for nanogram quantities of arsenic in natural waters by arsine generation followed by graphite furnace atomic abeorption epectrometry. Anal Chim Acta 1978;98:251-9.

9. Uthe JF, Freeman HC, Johnston JR, Michalik P. Comparison of wet ashing and dry ashing for the determination of arsenic in marine organisms, using methylated arsenicals for standands. J Aseoc Off Anal Chem 1974;57:1363-5.

10. Fishman M, Spencer R. Automated atomic abeorption opectrometric determination of total arsenic in water and streambed materials. Anal Chem 1977;49:1599_602.

11. Atallah RH, Kalman DA. On-line photo-axidation for the determination of organoarsenic compounds by atomic-abeorption opectrometry with continuous arsine generation. Talanta 1991;38: 167-73.

12. Niron DE, Mussmann GV, Eckdahl SJ, Moyer TP. Total arsenic in urine: palladium-persulfate vs nickel as a matrix modifier for graphite furnace atomic abeorption opectrophotomotry. Clin Chem 1991;37:1575-9.

13. Niron DE, Moyer TP. Arsenic analysia II: rapid separztion and quantification of inorganic arsenic plus metabolites and arsenobetaine from urine. Clin Chem 1992;38:2479-83.

14. Tyeon JF, Offley SG, Seare NJ, Kibble HAB, Fellows C. Determination of arsenic in a nickel-based alloy by flow injection hydride generation atomic abeorption spectrometry incorporating continuous-flow matrix isolation and stopped-flow pre-reduction procedures. J Anal At Spectrom-1992;7:315-22.

15. Velghe N, Campe A, Cloeys A. Semi-automated determinstion of $\mathrm{Hg}$ in fish. At Abeorbt Newsl 1978;17:37-42.

16. Stringer CE, Attrep M Jr. Comparison of digestion methods for determination of organoarsenicals in wastewater. Anal Chem 1979;51:731-4.

17. Kingston HM, Jassie LB. Microwave energy for acid decomposition at elevated temperatures and presoures using biological and botanical samples. Anal Chem 1986;58:2534-41.

18. Bock $R$. A handbook of decomposition methods in analytical chemistry. Glasgow: International Textbook Co., 1979.

19. Orheim RM, Bovee HH. Atomic absorption determination of nanogram quantities of arsenic in biological media. Anal Chem 1974;46:921-2.

20. Murer AJL, Abildtrup A, Poulsen OM, Christensen JM. Estimation of the method evaluation function for the determination of hydride-generating arsenic compounds in urine by flow-injection atomic-abeorption spectrometry. Talanta 1992;39:469-74. 